\title{
Tissue Factor (TF) Expression and Angiogenesis in Tumor Progression and Inhibition of Tumor Growth by Anti-TF Antibodies in Human Tissue Factor Knock-In Mice
}

Amy L. Volk ${ }^{1 *}$, Laura Johns ${ }^{1}$, Heena Beck ${ }^{2}$, Francis L. McCabe ${ }^{3}$, Patricia Rafferty ${ }^{1}$, Devon D. Egenolf ${ }^{1}$, Hillary Millar $^{3}$, Jin Lu $^{2}$, Barry Morse ${ }^{2}$, Mark Anderson ${ }^{3}$ and Peter J. Bugelski ${ }^{1}$

${ }^{1}$ Biologics Toxicology, Janssen Research \& Development, LLC, Radnor, PA, USA

${ }^{2}$ Molecular Discovery Technology, Janssen Research \& Development, LLC, Radnor, PA, USA

${ }^{3}$ Oncology Research, Janssen Research \& Development, LLC, Radnor, PA, USA

\begin{abstract}
Background: Tissue factor (TF) serves as the primary initiator of the extrinsic pathway of blood coagulation and mediates signaling via the protease activated receptor-2 (PAR2). TF is over-expressed in several tumor types and may facilitate tumor progression and angiogenesis. To test the hypothesis that inhibition of TF may have an anti-tumor effect, we induced pulmonary adenomas (PA) in human TF knock in (huTF-KI) mice with urethane and studied the relationship between expression of TF and mutations in K-ras with tumor progression and the effect of a monoclonal anti-TF antibody on growth of a transplantable lymphoma.
\end{abstract}

Methods: huTF-KI mice received 10 weekly intraperitoneal (i.p.) injections of urethane and samples of lung were collected at six week intervals between weeks 10 and 28. Expression of TF and von Willibrand factor (vWF) in PA were studied by immunohistochemistry $(\mathrm{IHC})$ and mutations in K-ras were studied by laser capture microdissection and polymerase chain reaction (LCM-PCR).

Results: IHC showed that expression of TF and VWF increased as pulmonary epithelial hyperplasias and PA progressed. Dual staining TF and VWF showed that areas of high expression of TF correlated with the tumor vasculature and LCM-PCR showed that mutation of K-ras correlated with expression of TF and the angiogenic switch in PA. Finally, an anti-huTF monoclonal antibody slowed the growth of transplantable urethane-induced lymphomas.

Conclusion: Taken together, these data suggest that expression of TF plays an important role in tumor progression and the angiogenic switch. These data also suggest that anti-TF antibodies may be a viable tumor immunotherapy.

Keywords: Monoclonal antibody; Knock-In mice; Angiogenesis; Immunotherapy; Ethylcarbamate

\section{Introduction}

Tissue factor (TF, also known as thromboplastin, CD142 and coagulation factor III) is a $47 \mathrm{kDa}$ single chain, 263 amino acid membrane glycoprotein that binds coagulation factors X and VIIa and thereby initiates the extrinsic pathway of the coagulation cascade $[1,2]$. In addition to its role in coagulation, the TF-VIIA complex has also been shown to signal via activation of the protease activated receptor 2 (PAR2) [3] which induces an array of angiogenic regulators and cytokines $[4,5]$.

TF is believed to play a role in tumor progression and the angiogenic switch [6-10]. The angiogenic switch, a term originally coined by Naumov et al. [11], describes the recruitment of newly formed blood vessels during the progression of cancer to sustain the tumor's nutrient supply. It is believed that many proangiogenic events cause the angiogenic switch to occur, including endothelial cell division or proliferation of local endothelial cells and the mobilization and recruitment of bone marrow-derived endothelial progenitor cells (EPCS) [12,13]. Morishita et al. [14] have demonstrated that the angiogenic switch occurs in normal alveolar capillary endothelium during progression of lung adenocarcinoma. Signaling via PAR2 has been shown to make an important contribution to the ability of TF to mediate the angiogenic switch [15].

TF is over-expressed on a number of tumor types, including prostate, breast, pancreas and non-small cell lung [6,7,16,17]. A number of mechanisms are believed to play a role in over-expression of TF by tumor cells. These include inactivation of p53, AKT activation/ PTEN inactivation, activation of EGFR and mutations of K-ras $[9,18]$. In particular, mutation of K-ras is thought to play a critical role in carcinogenesis as indicated by the high frequency of mutations identified in rodent and human cancers, including those of the lung $[19,20]$. Mutation of K-ras is often seen at the transition of carcinoma in situ-invasive carcinoma to adjacent adenocarcinomas [21]. The $\mathrm{K}$-ras protein is 189 amino acids in length. Codon 61 (CAA), located in Exon 2 of the K-ras gene, encodes for glutamine at amino acid 183 and is considered to be the wild-type residue. CGA and CTA, coding for

*Corresponding author: Amy L. Volk, Biologics Toxicology, Biotechnology Center of Excellence, Janssen Research \& Development, LLC, 145 King of Prussia Road, Radnor, PA 19087, USA, Tel: 610-407-8935; Fax: 610-8894525; E-mail: avolk@its.jnj.com

Received January 12, 2012; Accepted February 15, 2012; Published February 17,2012

Citation: Volk AL, Johns L, Beck H, McCabe FL, Rafferty P, et al. (2012) Tissue Factor (TF) Expression and Angiogenesis in Tumor Progression and Inhibition of Tumor Growth by Anti-TF Antibodies in Human Tissue Factor Knock-In Mice. J Carcinogene Mutagene S7:001. doi:10.4172/2157-2518.S7-001

Copyright: ( $) 2012$ Volk AL, et al. This is an open-access article distributed unde the terms of the Creative Commons Attribution License, which permits unrestricted use, distribution, and reproduction in any medium, provided the original author and source are credited. 
Citation: Volk AL, Johns L, Beck H, McCabe FL, Rafferty P, et al. (2012) Tissue Factor (TF) Expression and Angiogenesis in Tumor Progression and Inhibition of Tumor Growth by Anti-TF Antibodies in Human Tissue Factor Knock-In Mice. J Carcinogene Mutagene S7:001. doi:10.4172/21572518.S7-001

Page 2 of 7

Arginine and Leucine, respectively, are common mutations that occur at codon 61 [21]. According to the secondary structure, there is a turn located at AA 183-184. It is believed that a point mutation at either of these positions may result in a change in secondary structure resulting in increased enzymatic activity of K-ras [21].

Targeting of TF with anti-TF antibodies as an antitumor therapy has been postulated previously. For example, inhibition of tumor growth and metastases in a human breast cancer xenograft model by CNTO 859 has been reported [22]. However, in human xenograft models, an anti-huTF mAb targets only the tumor cells and not the murine TF that would be expressed by the tumor stroma. As the tumor stroma is a critical factor in the tumor microenvironment, failure to target the tumor stroma could limit the value of xenograft experiments.

Recently, we have described a strain of mice that are knocked-in for human TF (huTF-KI) $[23,24]$. In these mice, expression levels of huTF are similar to that of murine TF in wild-type mice. High levels of TF are expressed in the brain, heart and uterus, with lower levels expressed in the lung, kidney, ovary and small intestine. At the microscopic level, expression of huTF is principally associated with the microvasculature. HuTF is functionally active in these mice which have a normal life span and show no tendency for increased hemorrhage, fibrosis, or cardiac abnormality as described for other huTF-KI mice [25].

In this report, experiments were designed to study the role of TF in progression of pulmonary adenomas induced by urethane and the association with mutations in K-ras with expression of TF in huTF-KI mice. In addition, the ability of an anti-human TF antibody to inhibit the growth of a transplantable urethane-induced lymphoma syngeneic in huTF-KI mice is reported.

\section{Materials and Methods \\ Human TF Knock-In mice}

HuTF-KI mice were generated by replacing the first two exons of the mouse TF (muTF) gene with the huTF complete coding sequence, thus placing it under the control of the endogenous muTF promoter at physiological levels, as described previously [23]. For our experiments, male huTF-KI mice (4 to 6 weeks of age) were bred at ACE Animals, Boyertown, PA and SCID/beige mice (4 to 6 weeks of age) were obtained from Charles River Laboratories, Wilmington, DE. The mice were grouping housed (six mice per cage) in filter top cages. Autoclaved food and water were available ad libitum and the room had a 12 hour light/dark cycle in the pathogen-free vivarium at Centocor, Radnor PA. The Institutional Animal Care and Use Committee (IACUC) at Centocor approved all procedures. The mice were quarantined for at least two weeks and were identified by ear tags. Cage cards labeled with the source, sex, number of animals, group number, treatment, study number and IACUC protocol number were affixed to the cages.

\section{Animal care and euthanasia}

The mice were observed once daily for overt signs of metastasis and clinical signs were recorded. At the termination of the study, or mice exhibiting severe clinical signs [e.g. lethargy, depressed state, impaired movement or suffering severe or chronic pain and distress] that could not be relieved, mice were euthanized by $\mathrm{CO}_{2}$ asphyxiation at the discretion of animal facility personnel, in accordance with the guidelines established in Centocor's Animal Care and Use Policy Criteria for Euthanasia in Laboratory Animals.

\section{Urethane tumor induction}

Urethane (ethyl carbamate, Sigma, St. Louis, MO) was administered i.p. for 10 weeks to 50 male huTF-KI mice at a dose of $1 \mathrm{gm} / \mathrm{kg}$, dissolved in sterile $0.9 \% \mathrm{NaCl}$, as previously described [26]. On weeks 10,16 , 22 and 28, mice (10-12 mice/time point) were euthanized and their lungs were removed. The right lung tissue was collected, pooled and 1:4 lung tissue homogenate in PBS was produced for transplantation into SCID/Beige (10-12 mice/time point) recipient mice. The left lung was inflated with $10 \%$ neutral buffered formalin $(\mathrm{NBF})$. The tissues were then processed for microscopic examination, embedded in paraffin, sectioned at $5 \mu \mathrm{m}$ and stained with hematoxylin and eosin (H\&E). The adjacent serial sections were used for immunohistochemical staining.

\section{Lung homogenate transplantation}

On weeks 10, 16, 22 and 28, lung homogenates from huTF-KI mice that received urethane (10-12 mice/time point) were prepared 1:4 in PBS and injected s.c. into SCID/beige recipient mice (10-12 mice/time point). The SCID/beige mice were monitored daily for signs of tumor growth at the site of injection or metastases for six weeks at each time point.

\section{Immunohistochemical (IHC) staining}

For morphometric analysis, on weeks 10, 16, 22 and 28, serial sections were stained for TF and vWF. For staining TF, sections were treated with heat-induced epitope retrieval (HIER) in antigen retrieval citra solution (BioGenex, San Ramon, CA) for approximately 13 minutes, incubated with peroxide block and Power Block ${ }^{\mathrm{TM}}$, incubated overnight at $4^{\circ} \mathrm{C}$ with biotinylated anti-human $\mathrm{TF}$ monoclonal antibody $(10 \mu \mathrm{g} / \mathrm{mL})$ (American Diagnostica, Stanford, CT) in Common Antibody Diluent (BioGenex, San Ramon, CA) and finally for 20 minutes at room temperature (RT) with streptavidin-HRPconjugate (BioGenex).

To stain cells expressing vWF, sections were subjected to protease induced epitope retrieval (PIER) by incubating with proteinase $\mathrm{K}$ (Dako, Carpinteria, CA) for ten minutes at RT. Non-specific binding of proteins was blocked with normal goat serum. Sections were incubated with rabbit anti-vWF $(4 \mu \mathrm{g} / \mathrm{mL})$ (Millipore, Billerica, MA) for one hour at RT. Endogenous activity of peroxidase was quenched followed by amplification with biotinylated goat anti-rabbit IgG $(\mathrm{H}+\mathrm{L})(3 \mu \mathrm{g} /$ $\mathrm{mL}$ ) (Vector Laboratories, Inc., Burlingame, CA) for thirty minutes. Both stains detected cells with peroxidase conjugated streptavidin, visualized by $\mathrm{DAB}$ and counterstained with Mayer's Hematoxylin. Negative controls were used by omission of the primary antibodies.

\section{Immunofluorescent staining}

For double staining of TF and vWF, sections were deparaffinized with EZ Dewax (BioGenex) and heat-induced epitope retrieval (HIER) was performed using Citra Solution (BioGenex). Sections were incubated in Peroxide Block (BioGenex) to quench endogenous activity, followed by non-specific binding of proteins with normal goat serum protein block (BioGenex) and Power Block ${ }^{\mathrm{TM}}$ (BioGenex). A cocktail of primary antibodies (biotinylated monoclonal anti-human TF $(10 \mu \mathrm{g} /$ $\mathrm{mL}$ ) (American Diagnostica) and polyclonal rabbit anti-human vWF $(4 \mu \mathrm{g} / \mathrm{mL})$ (Chemicon International, Temecula, CA) was made using Common Antibody Diluent (Biogenex) and sections were incubated overnight at $4^{\circ} \mathrm{C}$. (Anti-human TF antibodies were biotinylated using 
Citation: Volk AL, Johns L, Beck H, McCabe FL, Rafferty P, et al. (2012) Tissue Factor (TF) Expression and Angiogenesis in Tumor Progression and Inhibition of Tumor Growth by Anti-TF Antibodies in Human Tissue Factor Knock-In Mice. J Carcinogene Mutagene S7:001. doi:10.4172/21572518.S7-001

a 'mouse on mouse' detection kit (BioGenex)). Sections were washed in PBS buffer and a cocktail of secondary streptavidin-horseradish peroxidase (HRP) conjugated goat anti-mouse IgG and Alexa Fluor 488 Tyramide (to detect sites of deposition of HRP) (Molecular Probes, Inc., Eugene, OR) and goat anti-rabbit IgG Alexa Fluor 568 F(ab')2 frag (Molecular Probes) antibody-fluorescent conjugates were added and incubated at RT for 20 minutes. Sections were washed in PBS buffer and cover slipped with mounting medium containing 4,6-diamidino2-phenylindole (DAPI) dihydrochloride counterstain (Molecular Probes)

\section{Imaging and morphometric analysis}

A Nikon Eclipse E800 (Nikon Corporation, Melville, NY) microscope and an Evolution ${ }^{\mathrm{TM}}$ MP 5.0 camera (Media Cybernetics, Inc. Bethesda, MD) were used for imaging. Images were captured using Image-Pro Plus software version 5.1 (Media Cybernetics) and analyzed without enhancement. For morphometric analysis, all lesions from one stained section per animal were evaluated using a $10 \mathrm{X}$ objective. A Macro was written in Image-Pro Plus to perform all measurements consistently and the following measurements were made: total area of lesion, perimeter of areas stained for vWF and area stained for TF.

\section{Laser capture micro-dissection (LCM)}

A total of 17 lesions were collected from various timepoints. 8 $\mu \mathrm{m}$ sections of each specimen were cut on a microtome, mounted on Arcturus PEN Membrane Frame slides (Applied Biosystems, Carlsbad, CA) and stored at $-80^{\circ} \mathrm{C}$ until staining and laser capture were performed. Paraffin was extracted from all tissue sections; sections were rehydrated and stained with Arcturus HistoGene stain (Applied Biosystems) following the manufacturer's instructions. Slides were air dried for approximately 30 minutes at RT prior to laser capture. Lesions were located on the Arcturus Veritas Microdissection system (Applied Biosystems) and images acquired using 20X magnification. Lesions greater than $50,000 \mu \mathrm{m}^{2}$ were selected for capture. Following identification of each lesion, a Macro Cap (Applied Biosystems) was placed on the region of interest and each lesion was captured using the cut and capture mode, with one lesion captured per cap. Genomic DNA (gDNA) was isolated from each lesion using the QIAamp DNA Micro Kit (Qiagen, Valencia, CA), following the manufacturer's instructions. Isolated gDNA was stored at $-20^{\circ} \mathrm{C}$ until analysis. DNA was isolated from kidney tissue as control.

\section{Mutational analysis of K-ras exon 2, codon 61 of LCM samples}

K-ras mutational analysis was performed by PCR amplifying exon 2 to detect the presence of mutations in codon 61. PCR amplifications were performed, in duplicate, using $5 \mathrm{ng}$ of DNA template per reaction and TaKaRa Ex Taq polymerase (TaKaRa Bio, Inc., Madison, WI). $264 \mathrm{~kb}$ products that included codon 61 were obtained with primers muLC- 8 and muLCM-10. The sequences of the primers to amplify K-ras gene fragment containing codon 61 were muLC-8: AATAAATGTAAGCTATCATTACTTCACATGC and muLCM-10: TCCAGACTGTGTTTCTCCCTTCTCAGGACTCC.

To perform mutational analysis, first, the PCR products were cleaned up (QIAquick PCR Purification Kit, Qiagen) and confirmed by agarose gel electrophoresis. Then, the PCR products were sequenced on the 3100 Genetic Analyzer (Applied Biosystems) using muLC-8 primer and BigDye Terminator v1.1, v3.1 (Applied Biosystems). The nucleotide sequences obtained were aligned with the known K-ras exon 2 fragment and the chromatographs were analyzed for the presence of specific mutations (Arg with CGA and Leu with CTA) at codon 61 for heterogeneous base calling.

Upon obtaining the nucleotide sequences of each PCR product, the sequences were analyzed for CAA (Gln, considered to be the wild-type codon), CGA (Arg) or CTA (Leu) at codon 61. The major base pair calling was determined by the ABI DNA sequence software. However, the minor base pair calling (minor peak within a major peak) to determine the possibility of mixed codons was assessed by visually examining the chromatograph peaks as well as by the actual trace values under each peak. The "bleed-through" effect of the first base into the second base in codon 61 was unlikely since A, G or T was not the preceding nucleotide. Additionally, to support mixed codon evaluation, cautionary measures were taken when designing primers for PCR amplification and subsequent sequencing so that the codon 61 would be situated in the middle of the amplified region rather than closer to the beginning. Precisely, codon 61 is located $134 \mathrm{bp}$ away from the initiation point of sequence amplification with primer $\mathrm{mLC}-8$, the region where the scanning intensity is typically robust and clean.

\section{Transplantation and treatment of urethane-induced lymphoma in HuTF-KI mice with anti-TF antibody}

In a separate study, the effects of CNTO 2559, a human/mouse chimeric IgG1 anti-tissue factor antibody, derived from $10 \mathrm{H} 10$ a murine ant-human TF antibody [27], on the transplantable, urethaneinduced lymphoma in male huTF-KI mice were studied. The ULA/01/00 cell line was adapted for culture from lymphoma induced by urethane and serially transplanted in male huTF-KI mice. Cells were sterile and mycoplasma-free and grown in Alpha MEM supplemented with $10 \%$ fetal bovine serum. ULA tumor cells $\left(5 \times 10^{5}\right.$ cells in $\left.50 \mu \mathrm{L}\right)$ were implanted subcutaneously (s.c.) into the fat of the pectoral region of huTF-KI mice (12 mice/group). Four hours after pectoral tumor cell implantation, the mice received twice weekly i.p. administration of CNTO 2559 at a dose of $20 \mathrm{mg} / \mathrm{kg}$ (12 mice/group). PBS control groups were included in the study (12 mice/group).

\section{Primary tumor volume}

Tumors were measured by caliper (width and length) twice weekly (Absolute Solar Digimatic Caliper, Mitutoyo Corporation, Aurora, IL) until Day 15 (12 mice/group). Measurements were taken by the same study coordinator to maintain consistency. Tumor volume was calculated based on formula $\mathrm{V}=(\mathrm{LxWxW} / 2)$.

\section{Data analysis and statistics}

All data generated from Image-Pro was exported to Microsoft Excel software (Microsoft Corporation, Redmond, WA). Microsoft Excel and GraphPad Prism 5 (GraphPad Software, Inc., San Diego, CA) were used to analyze and graph the raw data. P-values less than 0.05 were considered significant.

\section{Results}

\section{Urethane induced pulmonary adenomas in HuTF-KI mice}

Histopathologic examination of $\mathrm{H} \& \mathrm{E}$ sections from the left lung at $10,16,22$ and 28 weeks showed urethane-induced pulmonary lesions that ranged in size from $2 \times 10^{5} \mu \mathrm{m}^{2}$ to $12 \times 10^{5} \mu \mathrm{m}^{2}$. Lesions were not 
Citation: Volk AL, Johns L, Beck H, McCabe FL, Rafferty P, et al. (2012) Tissue Factor (TF) Expression and Angiogenesis in Tumor Progression and Inhibition of Tumor Growth by Anti-TF Antibodies in Human Tissue Factor Knock-In Mice. J Carcinogene Mutagene S7:001. doi:10.4172/21572518.S7-001

observed in the lungs of the control mice that did not receive urethane. As shown in Figure 1, the lesions increased in number and size as a function of time. Subcutaneous transplantation of homogenates from the right lung tissue from these mice into SCID/Beige recipients did not result in a transplantable lung adenocarcinoma, suggesting that the lesions had not progressed to carcinoma. However, a lymphoma that transplanted in huTF-KI mice was obtained. The obtained lymphoma was cultured and subsequently used for tumor studies with an anti-TF antibody.

\section{Immunohistochemical (IHC) staining and morphometric analysis for TF and vWF}

To enable further detailed morphometric analysis of staining for TF and vWF, serial sections stained for 72 individual lesions were analyzed. The results of representative samples of IHC staining for TF and vWF are shown in Figure 2A-Figure 2H. As shown in Figure 3A, all lesions stained for TF and the total area stained for TF increased with lesion size (Spearman coefficient of correlation $=0.780, \mathrm{P}<$ 0.001). In areas of normal lung, alveolar capillaries and macrophages were stained for TF while bronchiolar epithelial cells (BECS) showed little staining. Staining of the neoplastic lesions was heterogeneous; some lesions stained stronger than others and, within single lesions, the staining of individual cells was variable. As shown in Figure 3B, all lesions contained cells that expressed vWF. Staining for vWF increased as tumors increased in size (Spearman coefficient of correlation $=$

\section{Tumor Progression}

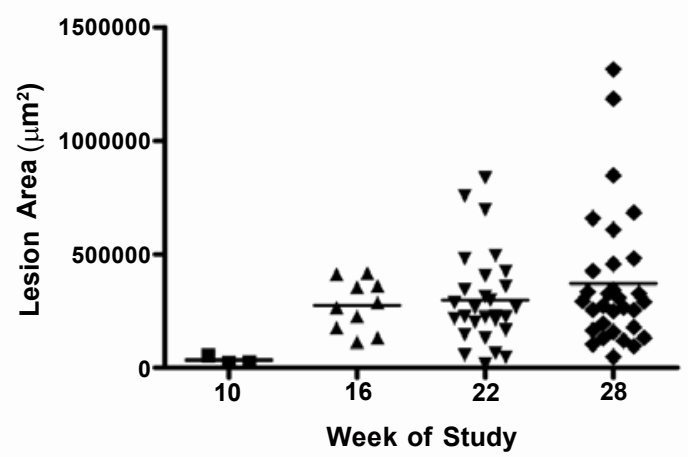

Figure 1: Tumor Progression. Morphometric analysis of H\&E sections from the left lung at 10,16, 22, and 28 weeks. Lesions were not observed in control mice that did not receive urethane.

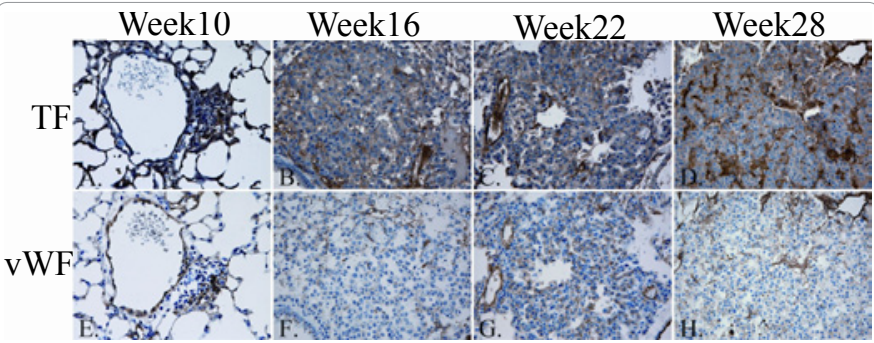

Figure 2: IHC Detection of TF and VWF. Representative sections of IHC staining for TF and VWF, 40x magnification. All lesions contained cells that stained positively for TF and VWF. Week 10 sections (A, E) show a small tumor growing around a blood vessel. Weeks 16,22 , and 28 sections (B, C, D, F, G, H) are predominantly occupied by tumor. Positive TF staining is seen in the alveolar capillaries and macrophages. Intra-lesion heterogeneity of TF expression is also present. TF expression is greatest in the neovascular-rich tumor stroma.
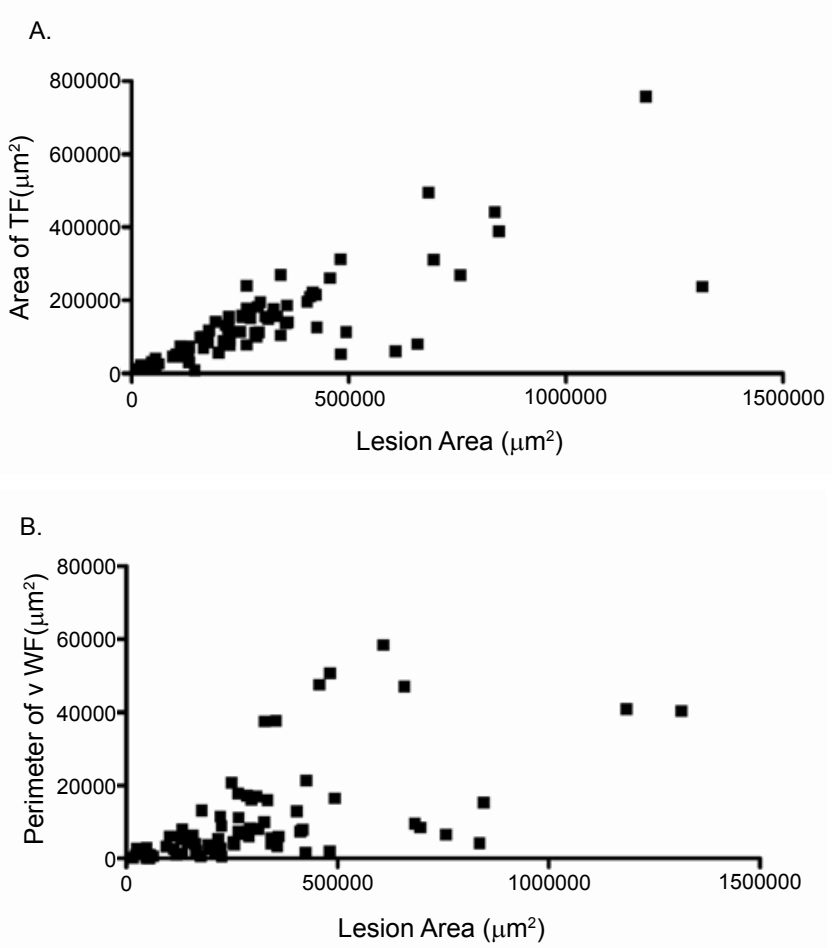

Figure 3: Increased Expression of TF and vWF. Morphometric analysis was performed on serial sections from all lesions analyzed to measure expression of TF and vWF. (A) All lesions stained for TF and the total area stained for TF increased with lesion size. (B) All lesions contained cells that expressed vWF and staining for VWF increased as tumors increased in size.

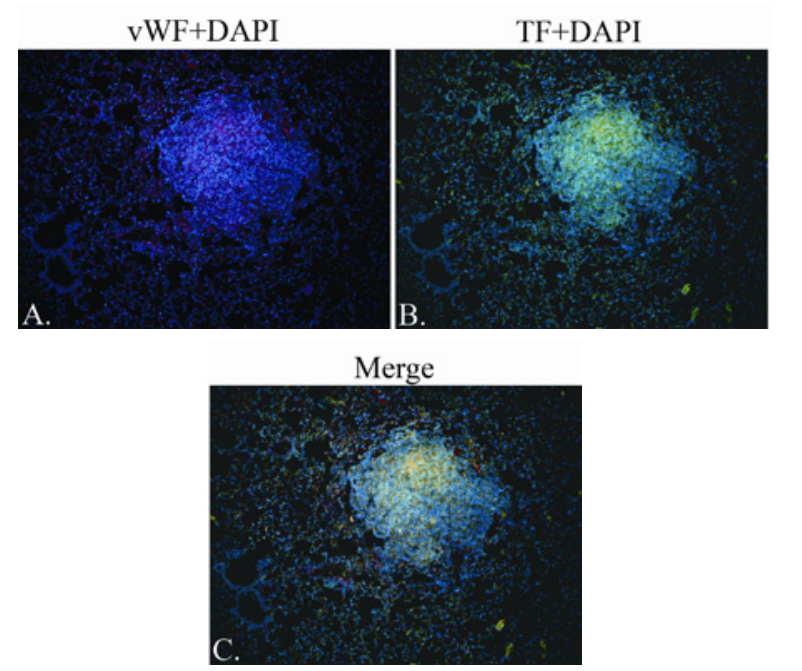

Figure 4: Fluorescent Detection of vWF and TF in Urethane-Induced Lung Tumors. Representative section triple-stained immunofluorescently (IF) for vWF (Alexa 568), TF (tyramide-Alexa 488), and DNA (DAPI), 10x magnification. Staining for TF was stronger within the lesions and the strongest staining for TF was co-localized with VWF. (A) Vascular endothelial cells (VECS) and pericytes have a positive stain for VWF. Pre-existing pulmonary vessels are observed outside of the lesion, and developing microvessels are noted within the lesion. The VWF staining pattern indicates that the existing vessels may be forming extensions as tumor microvessels. (B) TF was observed in tumor-associated blood vessels. TF was expressed by normal lung tissue, including alveolar capillaries, while bronchiolar epithelial cells (BECS) showed only weak staining for TF. (C) Expression of TF by tumor cells was highest in regions of active angiogenesis. 
Citation: Volk AL, Johns L, Beck H, McCabe FL, Rafferty P, et al. (2012) Tissue Factor (TF) Expression and Angiogenesis in Tumor Progression and Inhibition of Tumor Growth by Anti-TF Antibodies in Human Tissue Factor Knock-In Mice. J Carcinogene Mutagene S7:001. doi:10.4172/21572518.S7-001

Page 5 of 7

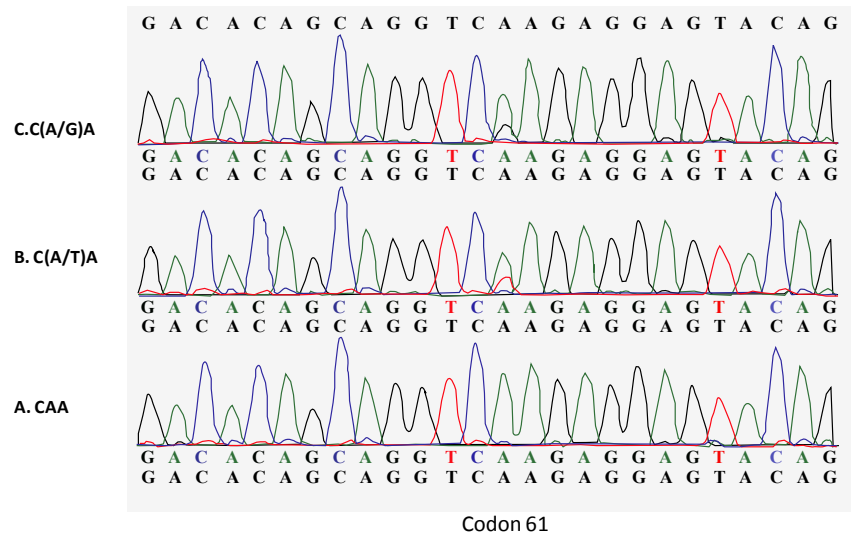

Figure 5: Chromatograms of nucleotide sequence analysis at and around codon 61. (A) The WT codon, CAA. (B) A mixture of CAA/ CTA codons shown by a minor peak of nucleotide "T" occurring under the major peak representing the second nucleotide of codon 61. (C) A mixture of CAA/ CGA codons shown by a minor peak " $G$ " occurring under the major peak representing the second nucleotide of codon 61

$0.651, \mathrm{P}<0.001)$. However, two populations of lesions were apparent, suggesting that the angiogenic switch occurred in some lesions when they reached approximately $3 \times 10^{5} \mu \mathrm{m}^{2}$ in sectional area (or assuming a spherical shape, approximately $1 \mathrm{~mm}$ in diameter). vWF staining was relatively low in some of the smaller lesions and was 2-3 fold higher in larger lesions, thus suggesting that the angiogenic switch occurred as the lesions progressed.

Urethane-Induced lesions triple-stained immunofluorescently (IF) for vWF (Alexa 568), TF (Tyramide-Alexa 488) and DNA (DAPI)

As shown in Figure 4A-Figure 4C, in sections triple-stained immunofluorescently (IF) for vWF (Alexa 568), TF (tyramide-Alexa 488) and DNA (DAPI), the vascular structures stained for vWF. Pre-existing pulmonary vessels were observed outside of the lesion, whereas developing microvessels were noted within the lesion. In some areas, the vWF staining pattern suggested that the pre-existing vessels may have formed extensions as tumor microvessels. TF was expressed by normal lung tissue, including alveolar capillaries, while bronchiolar epithelial cells (BECS) showed only weak staining for TF. Staining for TF was stronger within the lesions and the strongest staining for TF was co-localized with vWF (Figure 4C).

\section{Mutations by analysis of K-ras exon 2, codon 61 in urethane-} induced lesions

Nucleotide sequence analysis of codon 61 is shown in Figure 5A-Figure 5C. K-ras exon 2, codon 61 CGA and CTA mutations were present in 12/17 (70\%) of the urethane-induced lesions analyzed and was associated with the largest lesion sizes in this study. The remaining five lesions contained the wild-type K-ras allele. K-ras mutation also correlated with increased TF expression and increased vascularity (Figure 6A-Figure 6C).

Urethane-induced lymphoma triple-stained immunofluorescently (IF) for vWF (Alexa 568), TF (Tyramide-Alexa 488) and DNA (DAPI)

As shown in Figure 7A-Figure 7C, blood vessels and areas of angiogenesis were found in urethane-induced lymphoma tumors at Day 15. TF was found on the outside of the lesion, where it is normally expressed in the tumor stroma and newly formed blood vessels, but it was not found inside the lymphoma lesions, which lacks tumor stroma and tumor endothelial cells. TF and vascularity were colocalized in tumor stroma. The presence of blood vessels and angiogenesis indicate
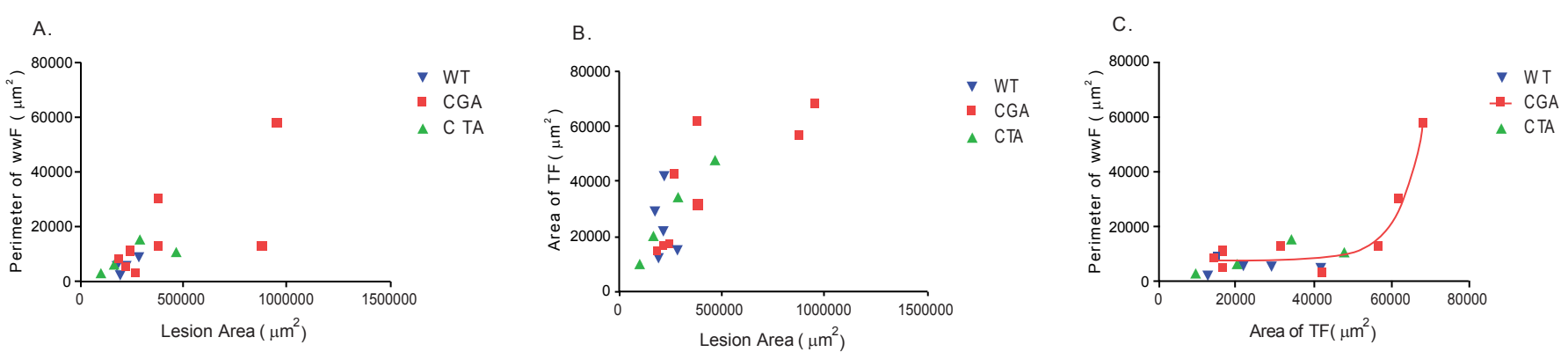

Figure 6: K-ras Mutation and Expression of VWF and TF. (A) The angiogenic switch occurred as the lesions progressed in size and as expression of vWF increased. WT expressed little vWF. (B) As the lesions progressed in size and vascularity, the expression of TF also increased. (C) K-ras mutation correlated with increased TF expression and increased vascularity $\left(R^{2}=0.9579\right)$

$\mathrm{vWF}+\mathrm{DAPI}$

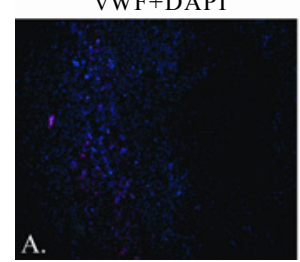

TF+DAPI

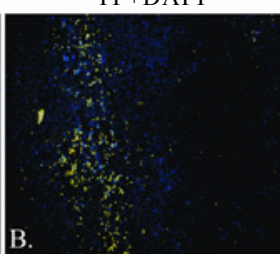

Merge

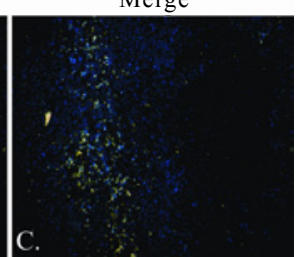

Figure 7: Fluorescent Detection of vWF and TF in Urethane-Induced Lymphoma. Representative sections triple-stained immunofluorescently (IF) for vWF (Alexa 568), TF (tyramide-Alexa 488), and DNA (DAPI), 10x magnification. (A) Blood vessels and areas of angiogenesis are present. (B) TF staining is strong within the tumor stroma but absent inside the tumor. (C) The strongest staining for TF is co-localized with vWF. vWF appears to be a subset of TF. 
Citation: Volk AL, Johns L, Beck H, McCabe FL, Rafferty P, et al. (2012) Tissue Factor (TF) Expression and Angiogenesis in Tumor Progression and Inhibition of Tumor Growth by Anti-TF Antibodies in Human Tissue Factor Knock-In Mice. J Carcinogene Mutagene S7:001. doi:10.4172/21572518.S7-001

Page 6 of 7

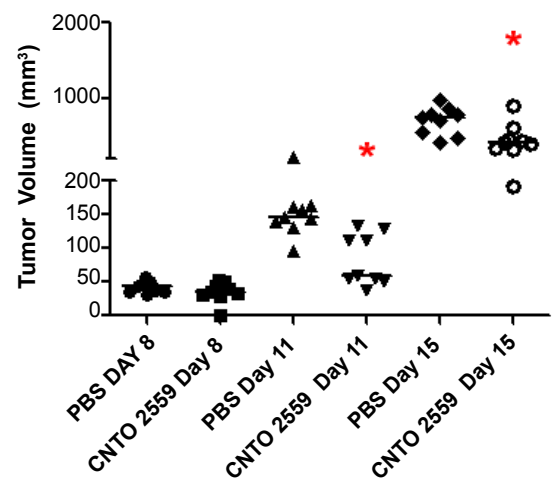

Figure 8: Effect of Tumor Suppression with anti-TF Antibody. Primary tumor volumes show statistically significant suppression of tumor growth on Days 11 and 15 for animals treated with anti-TF antibody, compared to PBS controls. The final median tumor volume for each group is shown. Asterisk $\left({ }^{*}\right)$ indicates statistically greater than control, Wilcoxon Signed Rank Test $(P<0.05)$.

that anti-TF antibody could be of therapeutic benefit in decreasing angiogenesis and TF cell signaling in progressing lymphoma tumor microenvironment.

\section{Suppression of primary tumor growth with anti-TF antibody treatment of transplanted urethane-induced lymphoma}

To determine if there was a difference in primary tumor growth, the volume of primary tumors was measured throughout the study from Day 1 to Day 15 (12 mice/group). The final median tumor volume for each group is shown in Figure 8(see supplementary data). Primary tumor volumes at Days 11 and 15 were statistically greater than control, Wilcoxon Signed Rank Test $(\mathrm{P}<0.05)$, indicating that the primary tumor volume of huTF-KI mice injected s.c. with urethaneinduced lymphoma cells increases over time without anti-TF antibody treatment. In contrast, treatment of the lesions with anti-TF antibody resulted in suppression of primary tumor growth.

\section{Discussion}

This study has shown that expression of TF and tumor size increased together during progression of pulmonary adenomas, expression of TF by tumor cells was highest in regions of active angiogenesis and tumor microvessels expressed high levels of TF. Furthermore, mutations in K-ras mutation correlated with expression of TF and vWF and the angiogenic switch. In transplanted lymphomas, TF and vWF were co-localized within the tumor stroma and treatment of the mice with an anti-TF mAb suppressed tumor growth. In this study, urethane was used to induce lung lesions that progressed in size over time. Originally described over 50 years ago [26], urethane-induced pulmonary adenomas have been tested extensively to understand murine lung carcinogenesis and the molecular events in developing tumors [28]. The interaction of two electrophillic metabolites of urethane, vinyl carbamate and an epoxy derivative, with DNA to form 7-(2-oxoethyl) guanine adducts has been suggested to be responsible for its genotoxicity and carcinogenicity [29].

Tissue Factor (TF) is the primary initiator of blood coagulation by the extrinsic pathway [1]. It has been shown to be abundant in the brain, lung and placenta and has been demonstrated in extravascular cells of many tissues including bronchial epithelia, mucosal epithelia and the adventitia of blood vessels $[30,31]$. TF expression has been previously observed in a variety of tumors, including prostate [16], breast [17], pancreatic [6] and lung [7]. Consistent with these previous findings, we observed TF expression in normal lung tissue, including alveolar macrophages and bronchial epithelia and within the neoplastic lesions in the urethane-induced lung tumors where we observed a correlation between TF expression and lesion size, suggesting that increased TF expression is associated with lesion progression.

In normal cells, expression of TF is believed to be controlled by a variety of transcription factors expressed by differentiated cells [32]. In inflammation, expression of TF is activated by an endothelial cell response, leading to an increased prothrombotic state, an increase in cell adhesion molecules and the down-regulation of fibrinolytic activity to stabilize fibrin deposition in the inflamed tissue [33]. TF expression may also be regulated by the inflammatory cytokines TNF- $\alpha$ and IL- $1 \beta$, or by bacterial lipopolysaccharide (LPS) [32]. In our study, expression of TF by tumor cells was not uniform and there was heterogeneous expression of TF. This has been described previously across different tumors from the same tissue of origin and also within individual tumors [34]. It is likely that tumors are intrinsically heterogeneous. This has been demonstrated in a colorectal carcinoma model, where distinct subpopulations of cells expressing high and low levels of TF could be identified within the same lesion [9]. In this same study, when the populations were isolated, the cells expressing high levels of TF grew aggressively and contained mutant K-ras allele, while the cells expressing low levels of TF were poorly tumorigenic and expressed the wild type K-ras allele.

In tumors, oncogenic events in cancer cells (e.g., expression of mutant K-ras, EGFR, PTEN or p53) have been shown to lead to an increase in expression of TF [18]. The most common mutation in lung cancer is in K-ras codon 12, being found in $15-30 \%$ of all lung cancers [35]. Several researchers have shown that urethane causes point mutations in codons 12, 13 and 61 in the K-ras gene. At codon 61, either AT to TA transversion or AT to GC transition occur and mutations in codon 61 have been found in urethane-induced lung carcinomas in A/J mice [36]. This mutation is linked to early stages of tumorigenesis and can be detected as early as 14 days after urethane treatment [37]. CGA was the mutation associated with the largest lesions in this study. It is possible that this mutation results in a greater disruption of secondary structure and leads to more significant disruption of normal K-ras activation and signaling than the CTA mutation.

\section{Conclusions}

In conclusion, the data presented here suggest that TF may play an important role in pulmonary oncogenesis and in driving the angiogenic switch. They also suggest that anti-TF antibodies may have a role in tumor immunotherapy, either as monotherapy or in combination with cytoreductive therapy.

\section{Acknowledgements}

The authors thank Denise Chroscinski and the staff of ACE Animals, Inc. for the breeding and maintenance of the huTF-KI mice, Catherine Ferrante for culture of the ULA cell line, Alison Rogers, Haiyan Jiang and Jill Carton for providing CNTO 2559, Mindi Walker for review of the manuscript and George Treacy for his continued support. This manuscript is dedicated in memory of Peter J. Bugelski.

\section{References}

1. Mackman N (2006) Role of tissue factor in hemostasis and thrombosis. Blood Cells Mol Dis 36: 104-107. 
Citation: Volk AL, Johns L, Beck H, McCabe FL, Rafferty P, et al. (2012) Tissue Factor (TF) Expression and Angiogenesis in Tumor Progression and Inhibition of Tumor Growth by Anti-TF Antibodies in Human Tissue Factor Knock-In Mice. J Carcinogene Mutagene S7:001. doi:10.4172/21572518.S7-001

2. Nemerson Y, Bach R (1982) Tissue factor revisited. Prog Hemost Thromb 6: 237-261.

3. Belting M, Ahamed J, Ruf W (2005) Signaling of the tissue factor coagulation pathway in angiogenesis and cancer. Arterioscler Thromb Vasc Biol 25: 15451550.

4. Albrektsen T, Sørensen BB, Hjortø GM, Fleckner J, Rao LV, et al. (2007) Transcriptional program induced by factor VIla-tissue factor, PAR1 and PAR2 in MDA-MB-231 cells. J Thromb Haemost 5: 1588-1597.

5. Hjortoe GM, Petersen LC, Albrektsen T, Sorensen BB, Norby PL, et al. (2004) Tissue factor-factor VIla-specific up-regulation of IL-8 expression in MDAMB-231 cells is mediated by PAR-2 and results in increased cell migration. Blood 103: 3029-3037.

6. Kakkar AK, Lemoine NR, Scully MF, Tebbutt S, Williamson RC (1995) Tissue factor expression correlates with histological grade in human pancreatic cancer. Br J Surg 82: 1101-1104.

7. Koomägi R, Volm M (1998) Tissue-factor expression in human non-smallcell lung carcinoma measured by immunohistochemistry: correlation between tissue factor and angiogenesis. Int J Cancer 79: 19-22.

8. Staton CA, Chetwood AS, Cameron IC, Cross SS, Brown NJ, et al. (2007) The angiogenic switch occurs at the adenoma stage of the adenoma carcinoma sequence in colorectal cancer. Gut 56: 1426-1432.

9. Yu JL, May L, Lhotak V, Shahrzad S, Shirasawa S, et al. (2005) Oncogenic events regulate tissue factor expression in colorectal cancer cells: implications for tumor progression and angiogenesis. Blood 105: 1734-1741.

10. Zhang Y, Deng Y, Luther T, Müller M, Ziegler R, et al. (1994) Tissue factor controls the balance of angiogenic and antiangiogenic properties of tumor cells in mice. J Clin Invest 94: 1320-1327.

11. Naumov GN, Akslen LA, Folkman J (2006) Role of angiogenesis in human tumor dormancy: animal models of the angiogenic switch. Cell Cycle 5: 17791787.

12. Gao D, Nolan DJ, Mellick AS, Bambino K, McDonnell K, et al. (2008) Endothelia progenitor cells control the angiogenic switch in mouse lung metastasis. Science 319: 195-198.

13. Shaked Y, Ciarrocchi A, Franco M, Lee CR, Man S, et al. (2006) Therapyinduced acute recruitment of circulating endothelial progenitor cells to tumors. Science 313: 1785-1787.

14. Morishita C, Jin E, Kikuchi M, Egawa S, Fujiwara M, et al. (2007) Angiogenic switching in the alveolar capillaries in primary lung adenocarcinoma and squamous cell carcinoma. J Nihon Med Sch 74: 344-354

15. Kasthuri RS, Taubman MB, Mackman N (2009) Role of tissue factor in cancer. $\mathrm{J}$ Clin Oncol 27: 4834-4838.

16. Abdulkadir SA, Carvalhal GF, Kaleem Z, Kisiel W, Humphrey PA, et al. (2000) Tissue factor expression and angiogenesis in human prostate carcinoma. Hum Pathol 31: 443-447.

17. Contrino J, Hair G, Kreutzer DL, Rickles FR (1996) Insitu detection of tissue factor in vascular endothelial cells: correlation with the malignant phenotype of human breast disease. Nat Med 2: 209-215

18. Rak J, Milsom C, May L, Klement P, Yu J (2006) Tissue factor in cancer and angiogenesis: the molecular link between genetic tumor progression, tumor neovascularization, and cancer coagulopathy. Semin Thromb Hemost 32: 54 70.

19. Devereux TR, Holliday W, Anna C, Ress N, Roycroft J, et al. (2002) Map kinase activation correlates with K-ras mutation and loss of heterozygosity on chromosome 6 in alveolar bronchiolar carcinomas from B6C3F1 mice exposed to vanadium pentoxide for 2 years. Carcinogenesis 23: 1737-1743.

20. Kawano R, Nishisaka T, Takeshima Y, Yonehara S, Inai K (1995) Role of point mutation of the K-ras gene in tumorigenesis of B6C3F1 mouse lung lesions induced by urethane. Jpn J Cancer Res 86: 802-810

21. Horio Y, Chen A, Rice P, Roth JA, Malkinson AM, et al. (1996) Ki-ras and p53 mutations are early and late events, respectively, in urethane-induced pulmonary carcinogenesis in A/J mice. Mol Carcinog 17: 217-223.

22. Ngo CV, Picha K, McCabe F, Millar H, Tawadros R, et al. (2007) CNTO 859, a humanized anti-tissue factor monoclonal antibody, is a potent inhibitor of breast cancer metastasis and tumor growth in xenograft models. Int J Cancer 120 1261-1267.

23. Snyder LA, Rudnick KA, Tawadros R, Volk A, Tam SH, et al. (2008) Expression of human tissue factor under the control of the mouse tissue factor promote mediates normal hemostasis in knock-in mice. J Thromb Haemost 6: 306-314.

24. He X, Han B, Mura M, Li L, Cypel M, et al. (2008) Anti-human tissue facto antibody ameliorated intestinal ischemia reperfusion-induced acute lung injury in human tissue factor knock-in mice. PLoS One 3: e1527.

25. Pawlinski R, Pedersen B, Erlich J, Mackman N (2004) Role of tissue factor in haemostasis, thrombosis, angiogenesis and inflammation: lessons from low tissue factor mice. Thromb Haemost 92: 444-450.

26. Nettleship A, Henshaw P, Meyer H (1943) Induction of pulmonary tumors in mice with ethyl carbamate (urethane). Journal of the National Cancer Institute.

27. Versteeg HH, Schaffner F, Kerver M, Petersen HH, Ahamed J, et al. (2008) Inhibition of tissue factor signaling suppresses tumor growth. Blood 111: 190199.

28. Malkinson AM (2001) Primary lung tumors in mice as an aid for understanding preventing, and treating human adenocarcinoma of the lung. Lung Cancer 32 265-279.

29. Avanzo JL, Mesnil M, Hernandez-Blazquez FJ, Mackowiak II, Mori CM, et al. (2004) Increased susceptibility to urethane-induced lung tumors in mice with decreased expression of connexin43. Carcinogenesis 25: 1973-1982.

30. Drake TA, Morrissey JH, Edgington TS (1989) Selective cellular expression of tissue factor in human tissues. Implications for disorders of hemostasis and thrombosis. Am J Pathol 134: 1087-1097.

31. Fleck RA, Rao LV, Rapaport SI, Varki N (1990) Localization of human tissue factor antigen by immunostaining with monospecific, polyclonal anti-human tissue factor antibody. Thromb Res 59: 421-437.

32. Mackman N (1995) Regulation of the tissue factor gene. FASEB J 9: 883-889.

33. Camerer E, Kolstø AB, Prydz H (1996) Cell biology of tissue factor, the principal initiator of blood coagulation. Thromb Res 81: 1-41

34. Milsom C, Yu J, May L, Meehan B, Magnus N, et al. (2007) The role of tumorand host-related tissue factor pools in oncogene-driven tumor progression. Thromb Res 120 Suppl 2: S82-91.

35. Vatan O, Bilaloglu R, Tunca B, Cecener G, Gebitekin C, et al. (2007) Low frequency of p53 and k-ras codon 12 mutations in non-small cell lung carcinoma (NSCLC) tumors and surgical margins. Tumori 93: 473-477.

36. Ohmori $\mathrm{H}$, Abe $\mathrm{T}$, Hirano $\mathrm{H}$, Murakami T, Katoh $\mathrm{T}$, et al. (1992) Comparison of Ki-ras gene mutation among simultaneously occurring multiple urethaninduced lung tumors in individual mice. Carcinogenesis 13: 851-855.

37. Ichikawa T, Yano Y, Uchida M, Otani S, Hagiwara K, et al. (1996) The activation of K-ras gene at an early stage of lung tumorigenesis in mice. Cancer Lett 107 165-170. 